archives

of thermodynamics

Vol. 37(2016), No. 4, 19-35

DOI: $10.1515 /$ aoter-2016-0025

\title{
The methodology of the gas turbine efficiency calculation
}

\author{
JANUSZ KOTOWICZ \\ MARCIN JOB \\ MATEUSZ BRZĘCZEK* \\ KRZYSZTOF NAWRAT \\ JANUSZ MĘDRYCH
}

Silesian University of Technology, Institute of Power Engineering and

Turbomachinery, Konarskiego 18, 44-100 Gliwice, Poland

\begin{abstract}
In the paper a calculation methodology of isentropic efficiency of a compressor and turbine in a gas turbine installation on the basis of polytropic efficiency characteristics is presented. A gas turbine model is developed into software for power plant simulation. There are shown the calculation algorithms based on iterative model for isentropic efficiency of the compressor and for isentropic efficiency of the turbine based on the turbine inlet temperature. The isentropic efficiency characteristics of the compressor and the turbine are developed by means of the above mentioned algorithms. The gas turbine development for the high compressor ratios was the main driving force for this analysis. The obtained gas turbine electric efficiency characteristics show that an increase of pressure ratio above 50 is not justified due to the slight increase in the efficiency with a significant increase of turbine inlet combustor outlet and temperature.
\end{abstract}

Keywords: Gas turbine; Polytropic efficiency; Isentropic efficiency

\section{Nomenclature}

$$
\begin{array}{ll}
0-9 & - \text { characteristic points } \\
a & - \text { air / flue gas } \\
A F & - \text { air filter }
\end{array}
$$

${ }^{*}$ Corresponding Author. E-mail: mateusz.brzeczek@polsl.pl 


$\begin{array}{lll}c & - & \text { cooling air } \\ C & - & \text { compressor } \\ C C G T & - & \text { combined cycle gas turbine } \\ C C H & - & \text { combustor chamber } \\ C O & - & \text { cooler } \\ C O T & - & \text { combustor outlet temperature } \\ \tilde{C} & - & \text { average specific heat } \\ G & - & \text { generator } \\ L H V & - & \text { lower heating value } \\ \dot{m} & - & \text { mass flow } \\ p & - & \text { pressure } \\ R & - & \text { individual gas constant value } \\ S C & - & \text { simple cycle } \\ t \text { or } T & - & \text { temperature } \\ T & - & \text { turbine } \\ T B C & - & \text { thermal barrier coatings } \\ T I T & - & \text { turbine inlet temperature } \\ \dot{Q} & - & \text { heat flux } \\ (C) & - & \text { conservative scenario } \\ (O) & - & \text { optimistic scenario }\end{array}$

\section{Greek symbols}

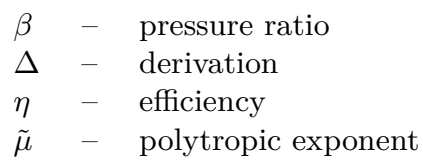

\section{Subscripts}

$\begin{array}{lll}\text { CCGT } & - & \text { combined cycle gas turbine } \\ e l & - & \text { electrical } \\ \text { est } & - & \text { establish } \\ f & - & \text { fuel } \\ F C & - & \text { fuel compressor } \\ \text { gross } & - & \text { gross } \\ G T & - & \text { gas turbine } \\ i & - & \text { internal/isentropic } \\ \text { in } & - & \text { inlet } \\ m & - & \text { mechanical } \\ m a x & - & \text { maximal } \\ n e t & - & \text { net } \\ \text { out } & - & \text { outlet } \\ p & - & \text { polytropic } \\ s & - & \text { waste heat } \\ S T & - & \text { steam turbine } \\ t & - & \text { thermal } \\ \zeta & - & \text { pressure loss } \\ \cdot & - & \text { division of subscripts } \\ & & \end{array}$




\section{Superscripts}

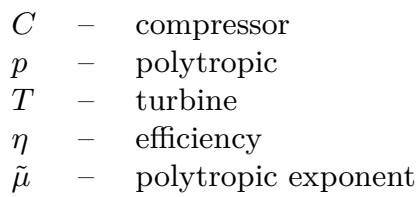

\section{Introduction}

Gas turbines are the machines consisting of the air compressor and the expander, mostly connected together by common shaft, and of a combustion chamber placed between them. In the energy sector these machines are used as an autonomous units called simple cycle (SC) or as a components of a gas turbine combined cycle gas turbine units (CCGT). The simple cycle units are characterized by lower powers and light, container-construction allowing for easy transport. Gas turbines used in CCGT units often have electric power exceeding $300 \mathrm{MW}$. In countries such as Poland, where the ratio of natural gas to coal prices is unfavorable - SC units are not built due to the lack of investment profitability, gas turbines are working there only in a combined cycle [1-3].

Thermal efficiency of CCGT units is defined by the relationship

$$
\eta_{t C C G T}=\frac{N_{\mathrm{iGT}}+N_{i S T}}{\dot{Q}_{i n}},
$$

where $N_{i G T}, N_{i S T}$ are internal power of gas turbine and steam turbine, respectively, and $\dot{Q}_{i n}$ is a heat flow fed to the gas turbine. Equation (1) can be rewritten as

$$
\eta_{t C C G T}=\eta_{t G T}+\eta_{t S T}\left(1-\eta_{t} G T\right)
$$

where $\eta_{t} G T$ and $\eta_{t} S T$ are the thermal efficiency of a gas turbine and steam turbine, respectively, and are defined as

$$
\begin{gathered}
\eta_{t G T}=\frac{N_{i G T}}{\dot{Q}_{i n}}, \\
\eta_{t S T}=\frac{N_{i S T}}{\dot{Q}_{4 a}},
\end{gathered}
$$

where $\dot{Q}_{4 a}$ is a heat flow at the gas turbine outlet. Relationship (2) is presented graphically in Fig. 1. 


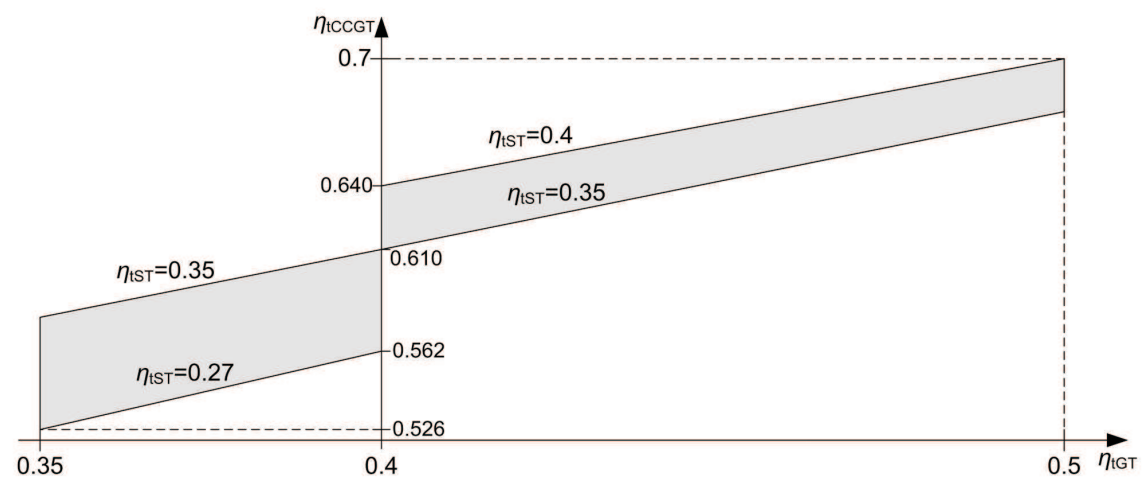

Figure 1: Thermal efficiency of the CCGT unit in a function of gas turbine and steam turbine cycle thermal efficiencies.

Currently achieved thermal efficiency of the gas turbines are around $40 \%$, and the steam turbine cycle they are up to above $35 \%$. Thus, the left side of vertical axis shows the currently achieved efficiency of the CCGT units. The right side of Eq. (2) represents the potential for increasing the CCGT efficiency. The derivation of Eq. (2) returns the condition for the CCGT efficiency increase

$$
\Delta \eta_{t C C G T}=\frac{\partial \eta_{t C C G T}}{\partial \eta_{t} G T} \Delta \eta_{t G T}+\frac{\partial \eta_{t C C G T}}{\partial \eta_{t} S T} \Delta \eta_{t S T} .
$$

Based on Eq.(5) for the values of $\Delta \eta_{t G T}=0.4$ and $\Delta \eta_{t S T}=0.35$ the derivatives of $\frac{\partial \eta_{t C C G T}}{\partial \eta_{t} G T} \cong 0.65$ and $\frac{\partial \eta_{t C C G T}}{\partial \eta_{t} S T} \cong 0.6$ are determined [1,2]. This means that the increase in the gas turbine efficiency $\Delta \eta_{t} G T$ by $1 \mathrm{pp}$ translates into a higher CCGT efficiency increase than in the analogous rise in steam turbine cycle $\left(\Delta \eta_{t S T}\right)$. This is the first argument suggesting a search direction to increase CCGT efficiency in the first place through the increase in gas turbine efficiency. The second, but much more important argument is the unit investment cost (referred to $1 \mathrm{MW}$ of generated power), which in the case of the gas turbine installation are 4-5 times lower than in steam turbine part. Therefore, the present paper concentrates on gas turbines [3-7].

The gas turbine efficiency depends primarily on the compressor pressure ratio and the highest temperature in the cycle, which is the combustor outlet temperature (COT). However, usually considered as the most important temperature in the gas turbine cycle is the average turbine inlet temperature (TIT), defined by ISO-2314 standard. For stoichiometric combustion 
conditions the COT would significantly exceed the value of $2000^{\circ} \mathrm{C}$. Today, most manufactures use the COT of $1500^{\circ} \mathrm{C}$. Only one of the leading producers introduced the COT at the level of $1600^{\circ} \mathrm{C}$, and conducts research towards the use of $1700^{\circ} \mathrm{C}[8,9]$. In comparison TIT achieves value range of $1300-1400^{\circ} \mathrm{C}$, rarely reaching $1500^{\circ} \mathrm{C}$.

Limitations of these temperatures result from the application of thermal barrier coatings (TBC), which cover elements exposed to the highest temperatures. Assumed that currently used TBC allow for continuous operation at a temperature not exceeding $1200^{\circ} \mathrm{C}$. Presently used cooling technologies allow for the flue gas temperature reduction at the cooled surface by $\Delta t=300-400 \mathrm{~K}$, therefore the highest temperature (COT or TIT) can reach $1500-1600{ }^{\circ} \mathrm{C}$. Raising TIT by 100 to $200 \mathrm{~K}$ is associated with the increase in $\Delta t$, i.e., to the value $\Delta t=500-600 \mathrm{~K}$. Such actions were the object of scrutiny of producers more than 10 years ago [10,11], but there is no information in the literature about their realization. An exception is the paper Hada et al. [12], from Mitsubishi Heavy Industries, Ltd., which indicates that the key to the creation of a J-class turbine with $T I T=1600{ }^{\circ} \mathrm{C}(\mathrm{M} 701 \mathrm{~J}$ and M501J for $50 \mathrm{~Hz}$ and $60 \mathrm{~Hz}$, respectively), i.e., the temperature higher by $100^{\circ} \mathrm{C}$ than the reference G-class, was to improve cooling technology and search for materials with lower thermal conductivity of TBC. Each of them allowed to increase TIT by $50{ }^{\circ} \mathrm{C}$. Data provided there also suggests that cooling technologies allow to reduce the surface temperature by $\Delta t=550 \mathrm{~K}$ in the G-class turbine, while the TBC with lowered temperature by $50 \mathrm{~K}$, allows to use the alloys with allowable temperature of $700-900{ }^{\circ} \mathrm{C}$. For the J-class turbine the cooling technology reduces surface temperature by $\Delta t=600 \mathrm{~K}$, and the TBC by $100 \mathrm{~K}$ (hence $\left.T I T=900+600+100=1600 ;{ }^{\circ} \mathrm{C}\right)$. In Japan there is also ongoing research on the turbine with $T I T=1700{ }^{\circ} \mathrm{C}[13]$.

In the case of the analyzes of gas turbines in a wide range of pressure ratio and TIT a significant mistake is to assume constant internal efficiency value, therefore the paper presents the calculation method of the gas turbine with variable isentropic efficiency of the compressor and the turbine depending on the pressure ratio and TIT.

\section{Gas turbine model}

The gas turbine is modeled using commercial PC-based software application for design and performance evolution of thermal power plant systems, 
GateCycle. Figure 2 shows a scheme of the gas turbine. Composition and parameters of ambient air are set according to ISO-2314 $\left(t_{0 \mathrm{a}}=15^{\circ} \mathrm{C}, p_{0 \mathrm{a}}=\right.$ $101.325 \mathrm{kPa}$ ). Assumed fuel is the natural gas composed of: $98.21 \% \mathrm{CH}_{4}$, $1.27 \% \mathrm{~N}_{2}$, and $0.52 \% \mathrm{CO}_{2}$, with temperature and pressure at the combustor inlet equal to $15^{\circ} \mathrm{C}$ and $3.5 \mathrm{MPa}$, respectively. The lower heating value (LHV) of the fuel is equal to $L H V=48110.54 \mathrm{~kJ} / \mathrm{kg}$ (according to ISO 6976:1995/1996). Table 1 summarizes the main parameters of the gas turbine installation.

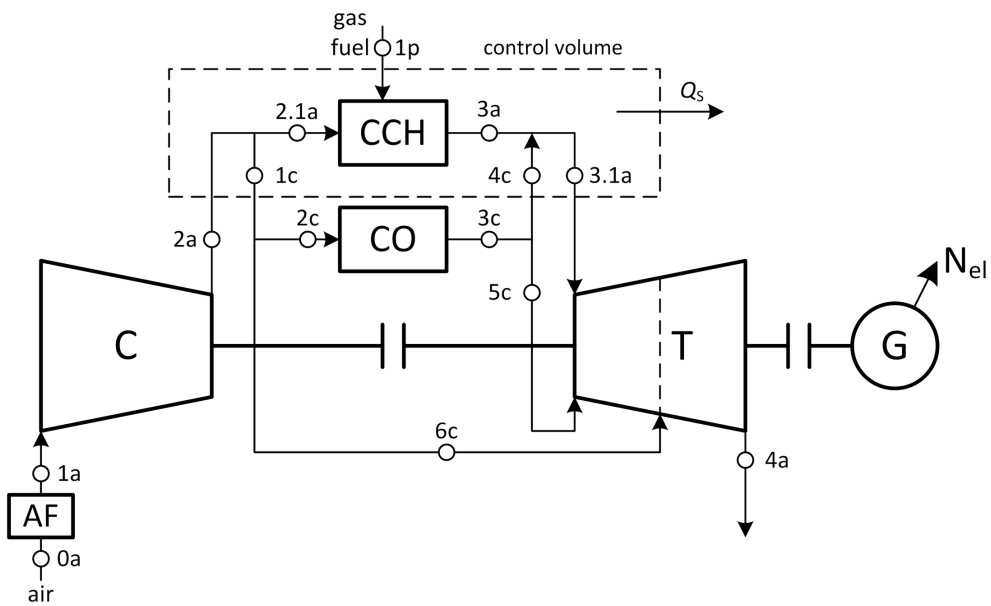

Figure 2: Scheme of the gas turbine: $\mathrm{AF}$ - air filter, $\mathrm{C}$ - compressor, $\mathrm{CO}$ - cooler, $\mathrm{CCH}$ - combustion chamber, $\mathrm{T}$ - turbine, $\mathrm{G}$ - generator, $Q_{s}$ - waste heat.

Table 1: The main parameters of the gas turbine installation.

\begin{tabular}{|l|c|c|c|}
\hline Parameter & Symbol & Value & Unit \\
\hline \hline Gas turbine electric power & $N_{e l ~ G T}$ & 200 & $\mathrm{MW}$ \\
\hline Mechanical efficiency & $\eta_{m}$ & 99.5 & $\%$ \\
\hline Generator efficiency & $\eta_{g}$ & 98.5 & $\%$ \\
\hline Compressor inlet pressure loss (air filter) & $\xi_{\text {in }}$ & 1 & $\%$ \\
\hline Combustion chamber pressure loss & $\xi_{C C H}$ & 4.5 & $\%$ \\
\hline Gas turbine outlet pressure loss & $\xi_{\text {out }}$ & 3.8 & $\%$ \\
\hline
\end{tabular}

The turbine cooling air flow is equal to $20 \%$ of the compressor inlet flow, from which $12 \%$ is cooled to $200{ }^{\circ} \mathrm{C}$ (3c) and used for cooling the combustor 
( $8 \%$ in $4 \mathrm{c})$ and the first stage of turbine ( $4 \%$ in $5 \mathrm{c}$ ), the remaining $8 \%$ is used for cooling the following turbine stages (6c).

The gas turbine outlet temperature is maintained at the level of $t_{4 \mathrm{a}}=630^{\circ} \mathrm{C}$. Depending on the pressure ratio, $\beta$, the COT is adjusted to obtain the desired temperature $\left(t_{3 \mathrm{a}}\right)$. Turbine outlet pressure is set at $p_{4 \mathrm{a}}=105.327 \mathrm{kPa}$, based on the outlet pressure loss

$$
p_{4 a}=\frac{p_{0 a}}{1-\xi_{\text {out }}}
$$

Isentropic efficiency of the compressor and the turbine are determinated on the basis of polytropic efficiency. Calculation path is presented in the following sections.

\section{Calculation algorithm of the compressor}

The compressor work does not depend on the parameters of the turbine, so in the first place calculations for the air compressor was performed to give the isentropic efficiency graph, $\eta_{i C}$ as a function $\beta$. The calculations are based on the compressor polytropic efficiency graph (Fig. 3), adopted on the basis of [14] for conservative (C) and optimistic (O) scenario.

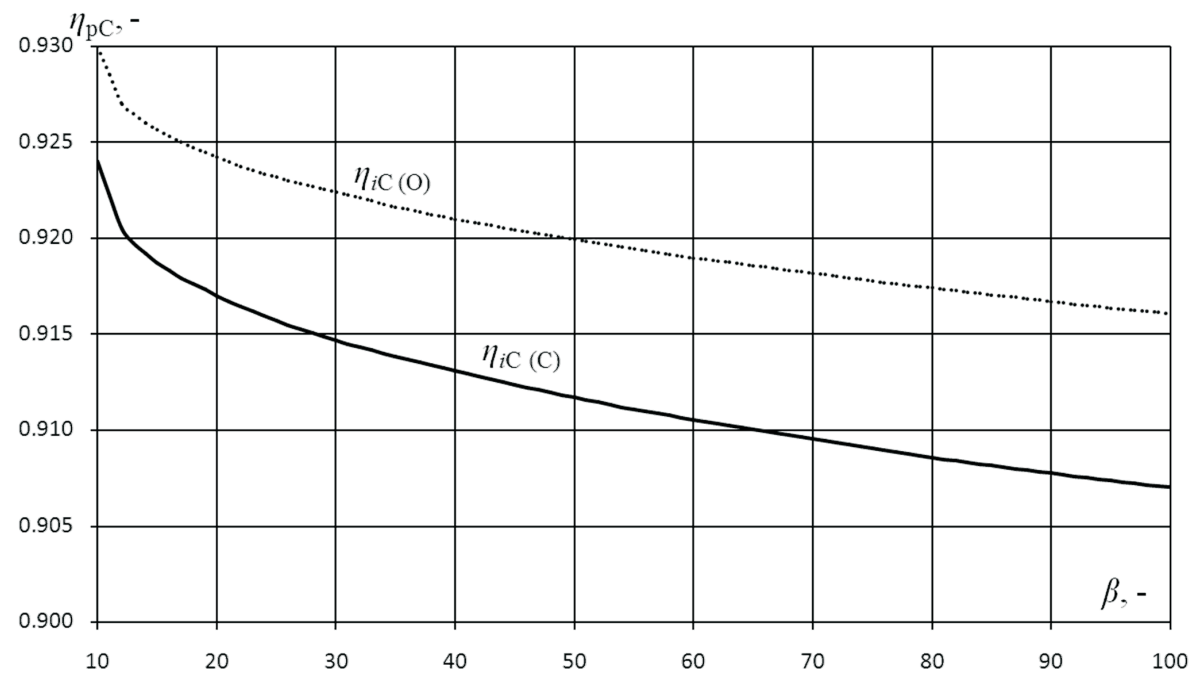

Figure 3: The compressor polytropic efficiency as a function of pressure ratio for conservative $(\mathrm{C})$ and optimistic $(\mathrm{O})$ scenario. 
Compressor isentropic efficiency is determined from the relationship described in [15]:

$$
\eta_{i C}=\frac{\beta^{\mu_{C}}-1}{\beta^{\frac{\mu_{C}}{\eta_{p}}}-1}
$$

where

$$
\widetilde{\mu}_{\mathrm{C}}=\frac{R}{\widetilde{C}_{p s C}}
$$

is the average isentropic exponent, $R$ is the individual gas constant value, and $\tilde{C}_{\mathrm{psC}}$ is the average specific heat for the isentropic conversion, here determined from relation

$$
\widetilde{C}_{p s C}=\frac{\left[C_{p s}\left(T_{1 a}\right) \ln \left(\frac{T_{1 a}}{T_{0}}\right)-C_{p s}\left(T_{2 a}\right) \ln \left(\frac{T_{2 a}}{T_{0}}\right)\right]}{\ln \left(\frac{T_{1 a}}{T_{2 a}}\right)}
$$

where $C_{p s}(T)$ is specific heat of air and its values are read for known temperatures $\left(T_{1 a}\right.$ and $\left.T_{2 a}\right)$, gas composition and the reference temperature $\left(T_{0}\right)$ from ideal gas parametric tables, e.g. $[15,16]$.

Block diagram of the calculation algorithm for the compressor is presented in Fig. 4. In a first place the compressor polytropic efficiency, $\eta_{p C}$, is read from the graph (Fig. 3) for the analyzed pressure ratio, $\beta$. Based on the Eqs. (7)-(9) isentropic efficiency of the compressor, $\eta_{i C}$, is calculated with initial assumption of $C_{p s}\left(T_{1 a}\right)=\widetilde{C}_{p s C}$. Then, compressor outlet temperature $T_{2 a}$ and current values of $\widetilde{C}_{p s C}$ and $\left(\eta_{i C}\right)_{t}$ are determined. The calculations are completed when the absolute difference between the previous and the current efficiency value is less than a predefined calculation precision, $\Delta \eta_{\max }$. Otherwise, the next iterations of compression calculations is performed for current efficiency until the predefined precision is complied.

The resulting characteristics of compressor isentropic efficiency are presented in Fig. 5, while the compressor outlet temperature is shown in Fig. 6. It is assumed that the maximum acceptable compressor outlet temperature is about $600{ }^{\circ} \mathrm{C}$ due to design restrictions. This temperature level is reached for pressure ratio $\beta=40$. Thus, to apply a higher $\beta$ a solution reducing the temperature is needed, e.g., compressor with air intercooling or the use of new materials. 


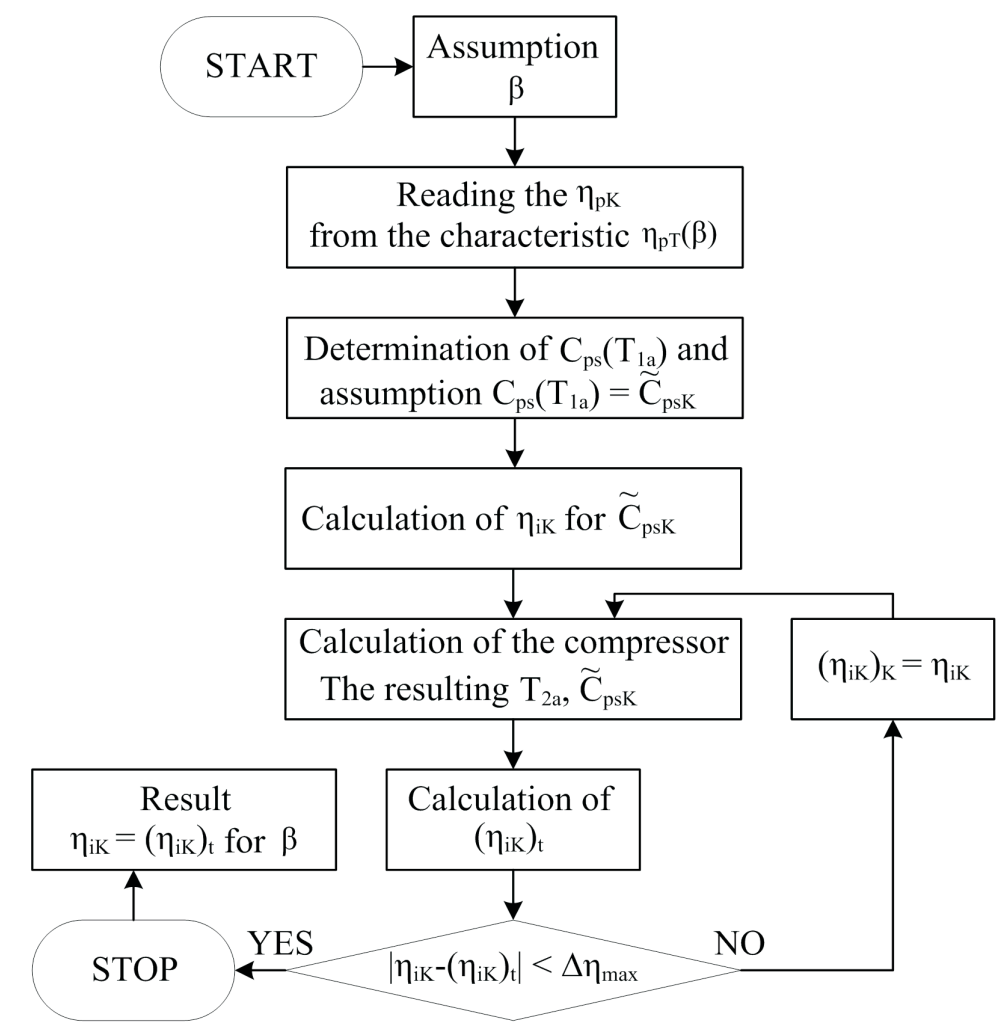

Figure 4: Block diagram of the calculation algorithm for the compressor.

\section{Calculation algorithm of the turbine}

The next step is to calculate the turbine isentropic efficiency, $\eta_{i T}$, on the basis of polytropic efficiency characteristics presented in Fig. 7, which depends mainly on the turbine inlet temperature and, in the second place, on the pressure ratio.

The value of $\beta=0$ is theoretical, to actual $\eta_{p T}$ value for assumed $\beta$ is obtained by adding the corresponding value according to the relation

$$
\eta_{p T}(\beta, T I T)=\eta_{p T}(T I T, \beta=0)+0.00225 \beta .
$$

The turbine inlet temperature is determined according to ISO-2314 standard [15]. It is a theoretical temperature before the first stage stationary blades. Simplification is here assumed that the total turbine cooling flow 


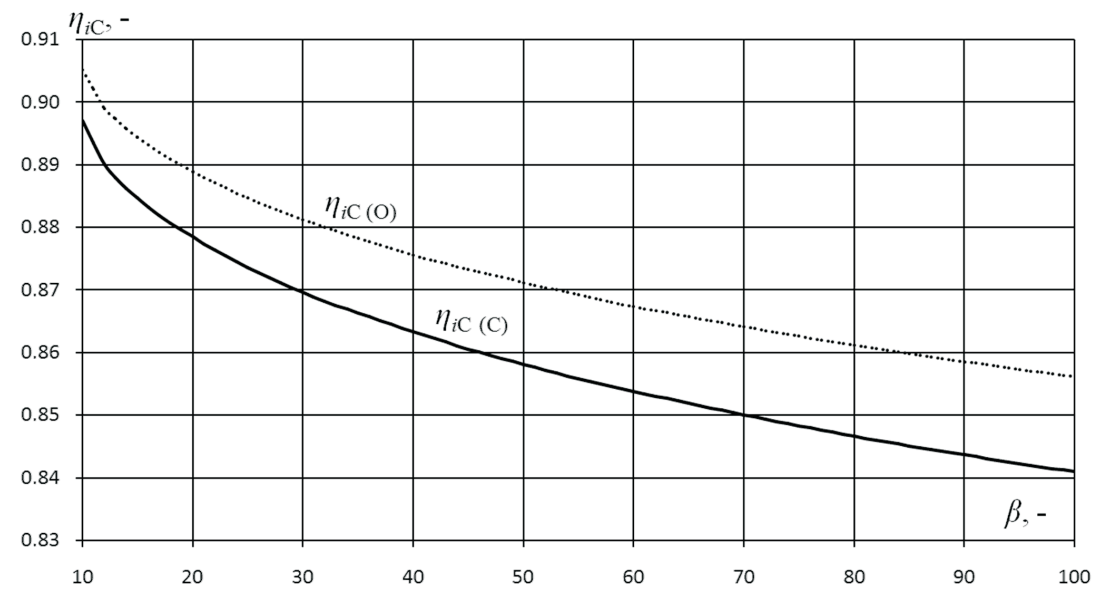

Figure 5: The compressor isentropic efficiency as a function of pressure ratio for conservative $(\mathrm{C})$ and optimistic $(\mathrm{O})$ scenario.

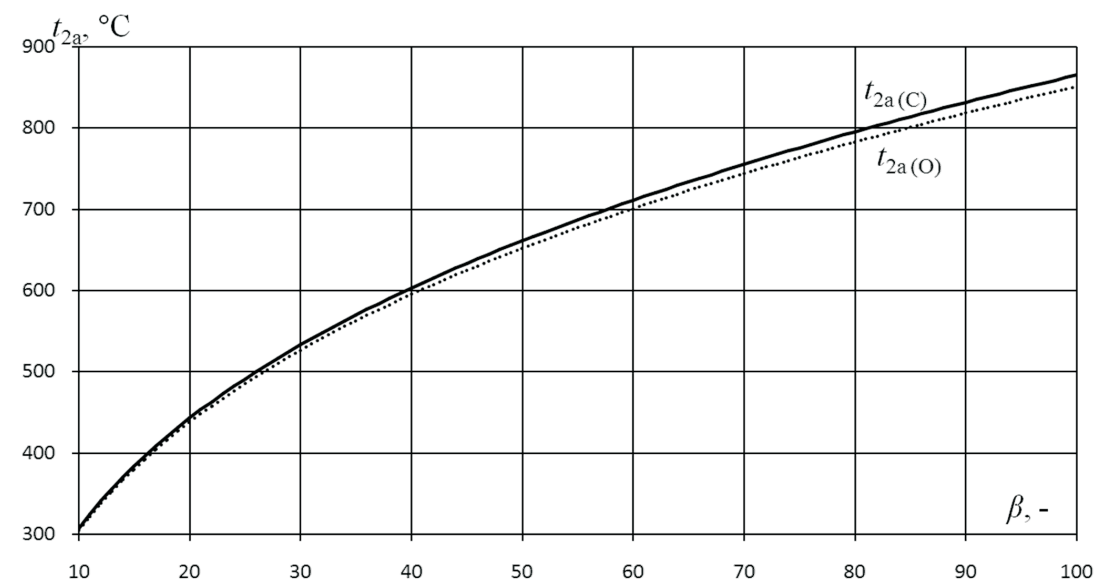

Figure 6: The compressor outlet temperature as a function of pressure ratio for conservative $(\mathrm{C})$ and optimistic $(\mathrm{O})$ scenario.

is mixed with the gas flow from combustor prior to entering the turbine, as illustrated in Fig. 8.

The turbine isentropic efficiency is determined from the relationship, described in detail in [15]

$$
\eta_{i T}=\frac{1-\beta^{-\mu T} \eta_{p T}}{1-\beta^{-\mu T}}
$$




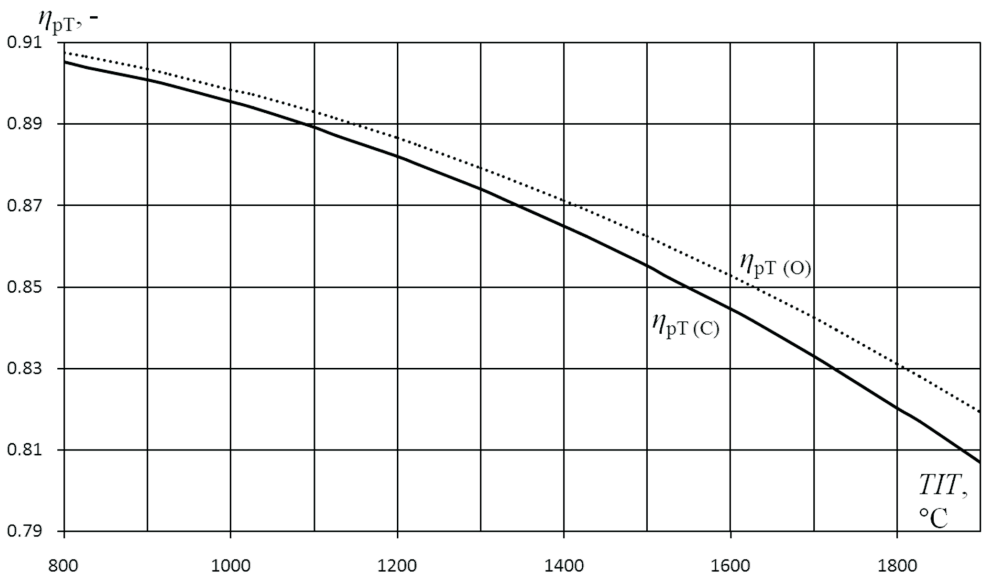

Figure 7: Turbine polytropic efficiency in function of turbine inlet temperature for $\beta=0$ for conservative $(\mathrm{C})$ and optimistic $(\mathrm{O})$ scenario.

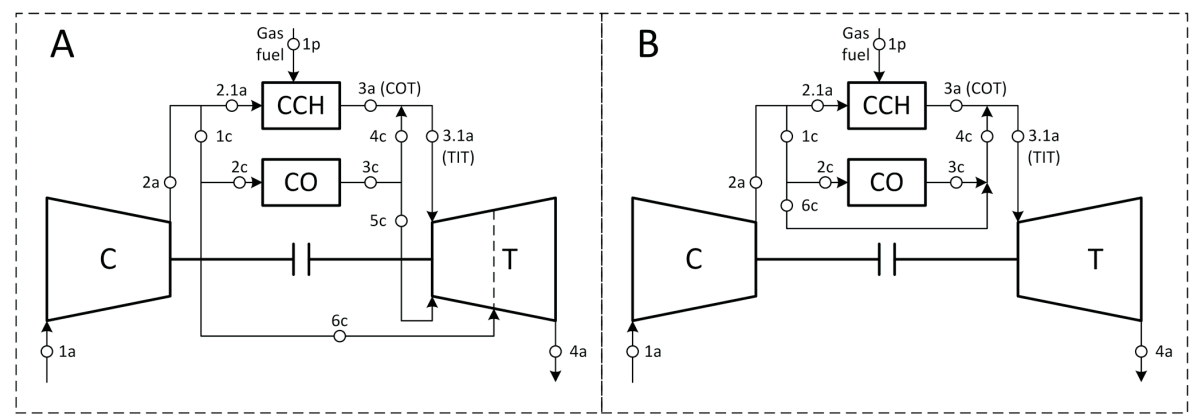

Figure 8: Diagram showing the relationship between the turbine inlet temperature (TIT) and the turbine cooling air: A - the real system, B - the system according to $[17]$.

where

$$
\widetilde{\mu}_{T}=\frac{R}{\widetilde{C}_{p s T}} .
$$

The average specific heat for isentropic conversion in turbine, $\tilde{C}_{p s T}$, is determined similar to (9) from relationship

$$
\widetilde{C}_{p s T}=\frac{\left[C_{p s}(T I T) \ln \left(\frac{T I T}{T_{0}}\right)-C_{p s}\left(T_{4 a}\right) \ln \left(\frac{T_{4 a}}{T_{0}}\right)\right]}{\ln \left(\frac{T I T}{T_{4 a}}\right)},
$$

where $C_{p s}(T)$ is specific heat of the flue gas with given composition and temperature, read from the ideal gas parametric tables, e.g., in $[15,16]$. 
If simplification in accordance with ISO-2314 is not applied, the calculation need to be done for each of the turbine stages resulting from the cooling, separately. This is caused by mixing of the flue gas with the cooling air, which changes the gas composition and temperature affecting its parameters $\left(\widetilde{C}_{p s T}\right)$. Calculation of $\eta_{i T}$ is performed iteratively according to the algorithm illustrated in Fig. 9. For the known compressor parameters

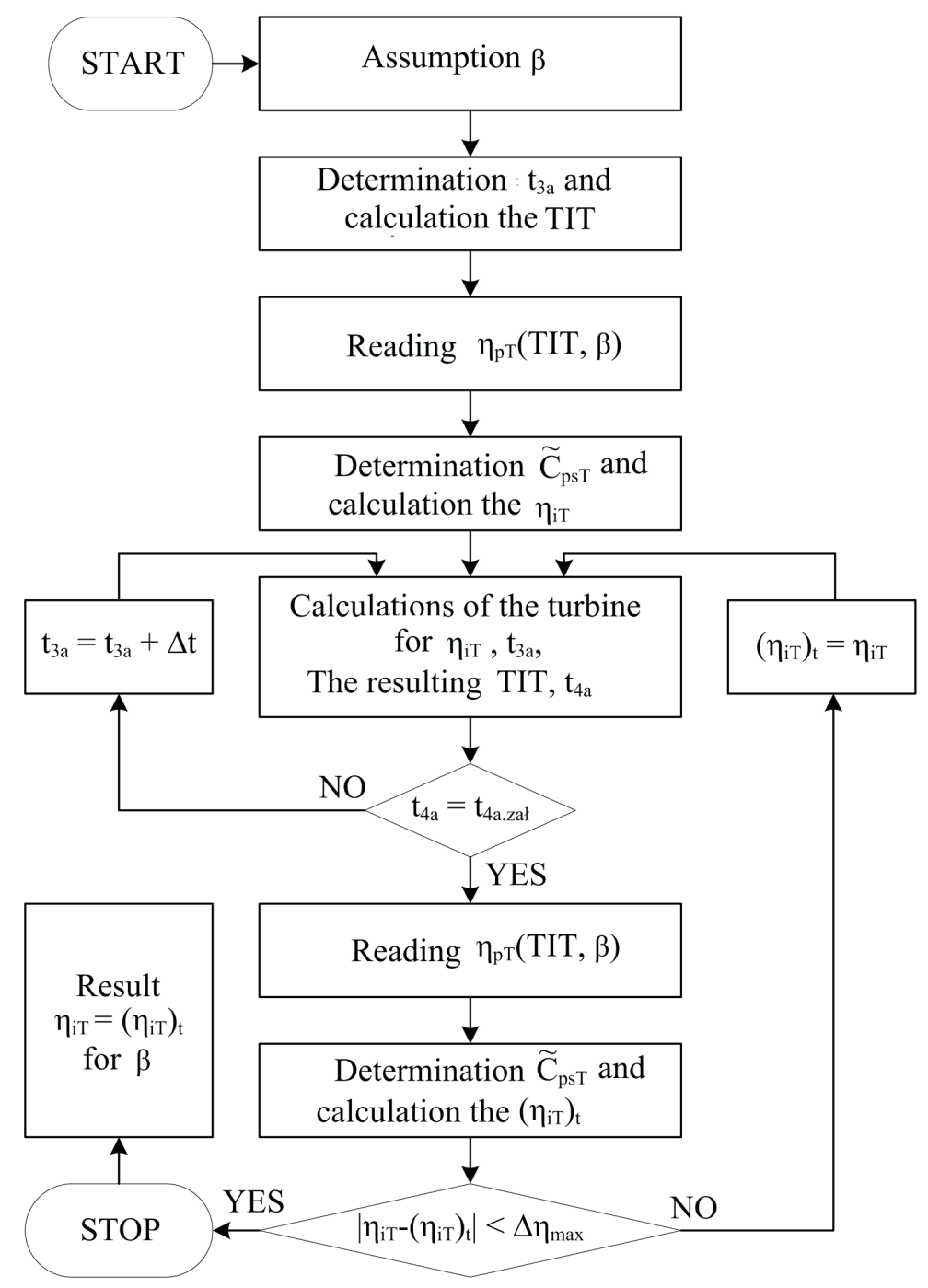

Figure 9: Block diagram of the calculation algorithm for the turbine. 
at given $\beta$ calculations for the turbine can be performed. The objective for the turbine is constant turbine outlet temperature $\left(t_{4 a}\right)_{e s t}=630^{\circ} \mathrm{C}$, which means that initially the combustor outlet temperature, $t_{3 a}$, and the resulting TIT, are unknown. Therefore, at first TIT must be determined on the basis of preassumed $t_{3 a}$. For given $\beta$ and initial TIT the turbine polytropic efficiency, $\eta_{p T}$, is read and basing on Eqs. (11)-(13) isentropic efficiency, $\eta_{i T}$, is calculated. Then, calculations for the turbine are performed and $\left(t_{4 a}\right)_{e s t}=t_{4 a}$ is not met, the small iteration loop is realized by adjusting $t_{3 a}$. After the temperature condition is fulfilled, the current values of $\eta_{p T}$ and $\eta_{i T}$ are re-determined for obtained results. In analogy to the compressor, turbine calculations are completed when the resulted $\left(\eta_{i T}\right)_{t}$ precision is met.

The obtained turbine isentropic efficiency characteristics are shown in Fig. 10, while the resulted temperatures of combuster outlet and turbine inlet are shown in Fig. 11. The resulting turbine isentropic efficiency can be applied only for the analyzed case, since they depend on TIT, $T_{4 \mathrm{a}}$ and flue gas composition. For new assumptions the efficiency must be recalculated according to the presented algorithm (Fig. 9).

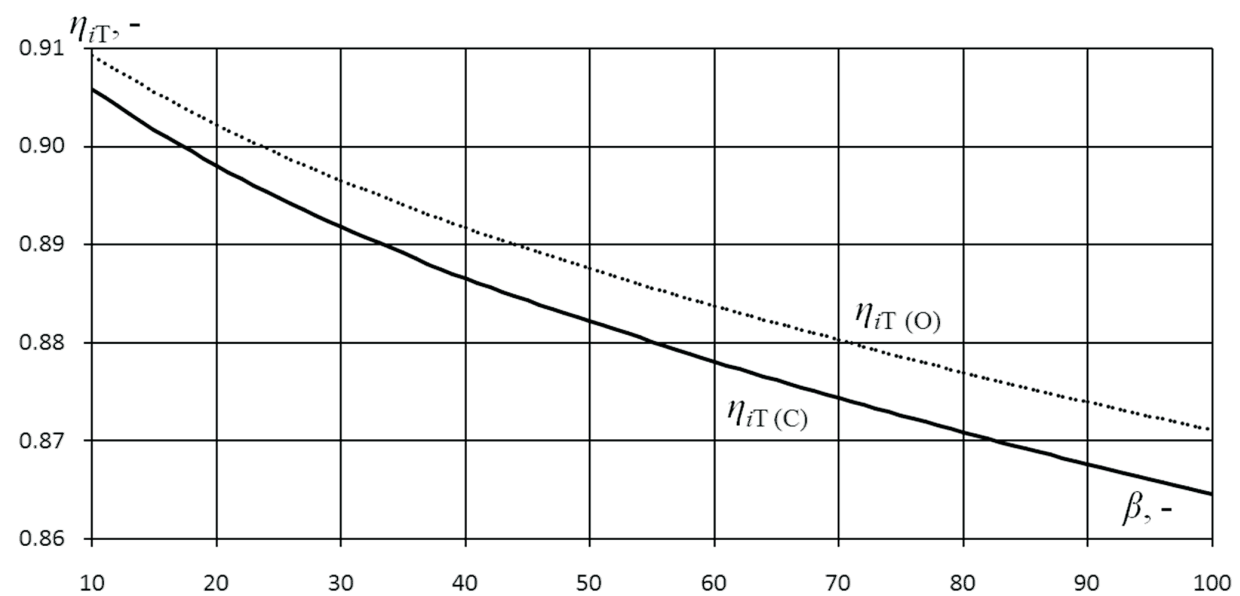

Figure 10: The turbine isentropic efficiency in as a function of pressure ratio as for conservative $(\mathrm{C})$ and optimistic $(\mathrm{O})$ scenario. 


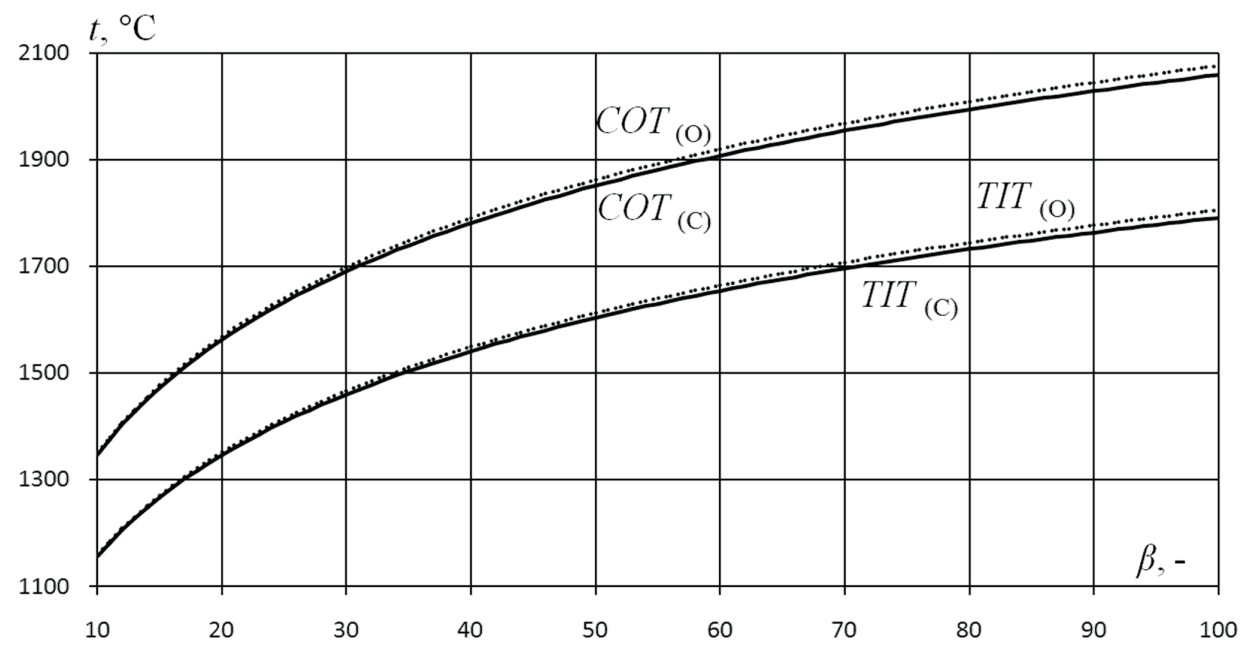

Figure 11: The temperatures of combuster outlet and turbine inlet as a function of pressure ratio for conservative $(\mathrm{C})$ and optimistic $(\mathrm{O})$ scenario.

\section{$5 \quad$ Gas turbine efficiency analysis}

Gross electric efficiency of the gas turbine, $\eta_{\mathrm{elGT} \text {.gross }}$, is determined using the lower heating value, $L H V$, of the fuel, according to relation

$$
\eta_{\text {elGT.gross }}=\frac{N_{e l G T}}{\dot{m}_{f} L H V},
$$

while the net efficiency takes into account the gas turbine own needs

$$
\eta_{\text {elGT.net }}=\frac{N_{\text {elGT.gross }}-\Delta N_{G T}+N_{F C}}{\dot{m}_{f} L H V},
$$

where $\dot{m}_{f}$ is the mass flowrate of fuel. The gas turbine own needs, $\Delta N_{G T}$, are assumed to be $0.22 \%$ of the gas turbine electric power, $\Delta N_{G T}$, and $N_{F C}$ is the fuel compressor power. The resulting gross and net electric efficiency of the gas turbine in function of the pressure ratio are shown in Fig. 12. Chosen characteristic parameters of the gas turbine installation for maximum achieved efficiency are summarized in Tab. 2.

\section{Conclusions}

A relatively high cost of the steam turbine installation compared to the gas turbine determines the direction of the combined cycle gas turbine unit 


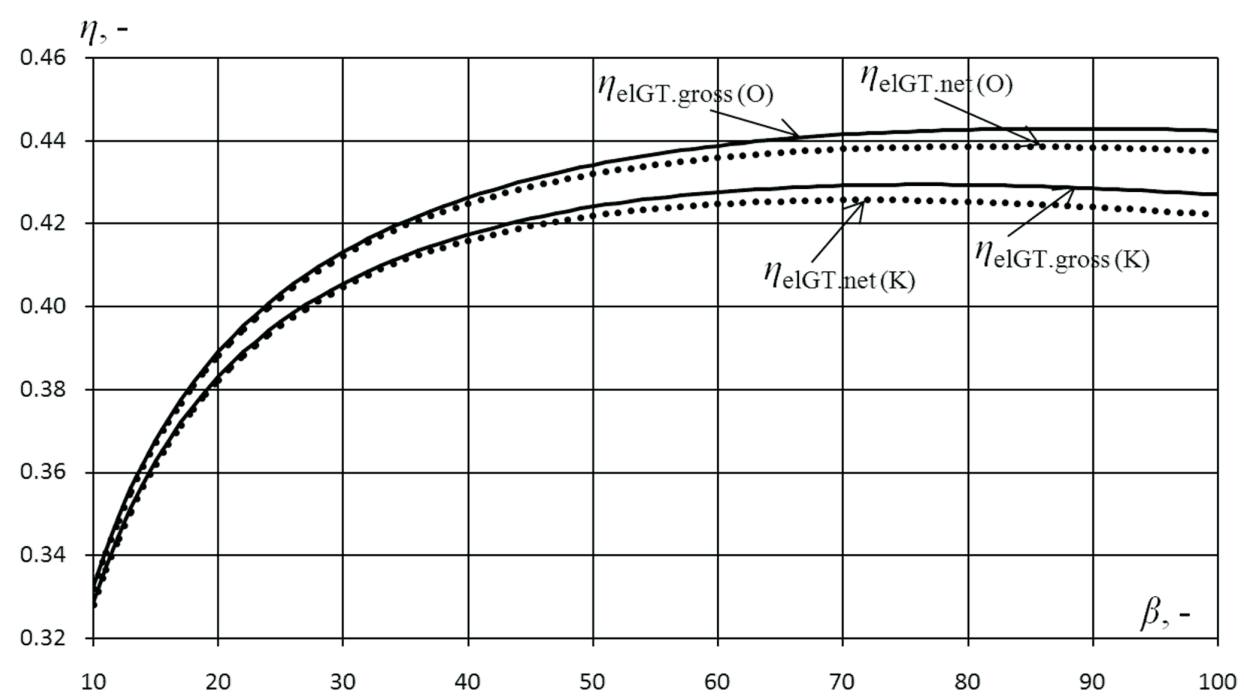

Figure 12: Gross and net efficiency of the gas turbine installation as a function of pressure ratio for conservative $(\mathrm{C})$ and optimistic $(\mathrm{O})$ scenario.

Table 2: Characteristic parameters of the gas turbine installation for chosen $\beta$.

\begin{tabular}{|c|c|c|c|c|c|}
\hline Symbol & Unit & \multicolumn{2}{c|}{ Conservative scenario $(\mathrm{C})$} & \multicolumn{2}{c|}{ Optimistic scenario (O) } \\
\hline \multicolumn{2}{|c|}{ Function max. } & $\eta_{\text {elGT.gross }}$ & $\eta_{\text {elGT.net }}$ & $\eta_{\text {elGT.gross }}$ & $\eta_{\text {elGT.net }}$ \\
\hline \hline$\beta$ & - & 76 & 71 & 87.0 & 82 \\
\hline$C O T$ & ${ }^{\circ} \mathrm{C}$ & 1979.2 & 1958.8 & 2034.7 & 2016.7 \\
\hline$T I T$ & ${ }^{\circ} \mathrm{C}$ & 1718.9 & 1700.5 & 1768.0 & 1751.8 \\
\hline$\eta_{i T}$ & - & 0.8723 & 0.8740 & 0.8748 & 0.8764 \\
\hline$\eta_{i C}$ & - & 0.8480 & 0.8497 & 0.8593 & 0.8607 \\
\hline$t_{2 a}$ & ${ }^{\circ} \mathrm{C}$ & 779.6 & 759.3 & 807.9 & 790.1 \\
\hline$\eta_{\text {elGT.gross }}$ & - & 0.4294 & 0.4293 & 0.4429 & 0.4428 \\
\hline$\eta_{\text {elGT.net }}$ & - & 0.4256 & 0.4257 & 0.4385 & 0.4386 \\
\hline
\end{tabular}

efficiency increase. Current barrier of net electric efficiency of the CCGT plant amounting $61 \%$ can be exceeded in the near future through the increase in the gas turbine efficiency, what can be realized in two ways. The first concept is to use gas turbines with standard pressure ratios (about 20), with a high turbine inlet temperature at the level of $1700^{\circ} \mathrm{C}$ (J-class turbines). The condition for success is the use of modern gas turbine cooling 
concepts (steam cooling) and the reduction of $\mathrm{NO}_{x}$ emission. An alternative solution is the use of higher pressure ratios at the level of 40-50 with lower TIT (about $1500-1550^{\circ} \mathrm{C}$ ).

The presented calculation algorithms allowed to obtain isentropic efficiency characteristics for the compressor and the turbine depending on the pressure ratio and the turbine inlet temperature.

The analysis revealed that the gas turbine efficiency reaches its optimum at a range of high pressure ratios $(\beta=70-90)$. However, for such high $\beta$ the compressor outlet temperature is far beyond $600^{\circ} \mathrm{C}$, temperature limit in the compressor. Thus, the use of such high $\beta$ would require fundamental modifications in the compressor design, e.g., by using a two-stage compressor with intercooling of the compressed air. The resulting TIT values for the pressure ratios above 40 also exceed the values in modern gas turbines. The use of such high temperatures requires a more efficient cooling of the turbine blades or the use of more durable materials.

The obtained gas turbine electric efficiency characteristics shows that an increase of pressure ratio above 50 is not justified due to the slight increase in the efficiency with a significant growth of compresor outlet and turbine inlet temperatures.

Received April 2014

\section{References}

[1] Chmielniak T.: Energy Technologies. WNT, Warsaw 2008 (in Polish).

[2] Szargut J., ZięBiK A.: Fundamentals of Thermal Energy. PWN, Warsaw 1998 (in Polish).

[3] Kotowicz J.: Combined Cycle Power Plants. Wydawnictwo Kaprint, Lublin 2008 (in Polish).

[4] Kotowicz J., BARTela Ł.: The thermodynamic and economic optimization of a gas-steam power plant by means of genetic algorithms. Rynek Energii 75(2008), 2, 31-38 (in Polish).

[5] Kotowicz J., Bartela Ł.: The influence of economic parameters on the optimal values of the design variables of a combined cycle plant. Energy 35(2010), 2, 911919.

[6] Kотоwicz J., Јов M.: Thermodynamic and economic analysis of a gas turbine combined cycle plant with oxy-combustion. Arch. Thermodyn. 34(2013), 4, 215-233.

[7] Kotowicz J., Bartela Ł.: Analysis of operation of the gas turbine in a poligeneration combined cycle. Arch. Thermodyn. 34(2013), 4, 137-159. 
[8] Heavy Duty Gas Turbines $\&$ Combined Cycle. General Electric. http://site.geenergy.com/prod_serv/products/gas_turbines_cc/en/index.htm (accessed on 15.04.2014).

[9] Gas turbines. Mitsubishi Heavy Industries, Ltd. http:www.mhi.co.jp/en/products/ category/gas_turbin.html (accessed on 15.04.2014).

[10] Facchini B., Innocenti L., Carvnevale E.: Evaluation and comparison of different blade cooling solutions to improve cooling efficiency and gas turbine performances. In: Proc. ASME Turbo Expo 2001, 2001-GT-0571, June 2001, New Orleans.

[11] JoRDAL K. et al.: New possibilities for combined cycles through advanced steam technology. In: Proc. ASME Turbo Expo 2002, GT-2002-30151, June 2002, Amsterdam, The Netherlands.

[12] Hada S., Yuri M., Masada J., Ito E., Tsukagoshi K.: Evolution and future trend of large frame gas turbines a new 1600 degree $C$, J class gas turbine. In: Proc. ASME Expo 2012, GT2012-68574, June 11-15, 2012, Copenhagen.

[13] Ito E., Okada I., Tsukagoshi K., Muyama A., Masada J.: Development of key Technologies for next generation gas turbine. In: Proc. ASME Turbo Expo 2007: Gas Turbine Technical Congress and Exposition, GT2007-41023, May 17-20, 2007, Montreal.

[14] Wettstein H.E.: The potential of GT combined cycles for ultra high efficiency. In: Proc. ASME Turbo Expo 2012, GT2012-68586. Denmark, 2012.

[15] Chmielniak T., Rusin A., Czwiertnia K.: Gas Turbines. Ossolineum, Wrocław 2001 (in Polish).

[16] Szargut J.: Thermodynamics. PWN, Warsaw 2000 (in Polish).

[17] ISO 2314:2009 Standard: Gas turbines - Acceptance tests. 